\title{
Florida child care center directors' intention to implement oral health promotion practices in licensed child care centers
}

\author{
Ajay Joshi ${ }^{1}$, Romer Ocanto ${ }^{2}$, Robin J. Jacobs ${ }^{3}$ and Vinodh Bhoopathi ${ }^{4^{*}}$
}

\begin{abstract}
Background: To determine the factors associated with child care center directors' (CCCDs) intention to implement oral health promotion practices (OHPPs) in licensed childcare centers (CCCs) within the next year, and their selfperceived barriers in successfully implementing those practices.

Methods: For this cross-sectional study, a pretested 45-item online survey was sent to 5142 CCCDs assessing pediatric oral health knowledge, attitudes towards oral health, intention to implement OHPPs, and self-perceived barriers to implementing OHPPs. An adjusted logistic regression model determined the factors associated with CCCDs intention to implement OHPPs within the next year.

Results: Participants were 877 CCCDs, with mean age of $48.5 \pm 10.5$ years, of whom $96 \%$ were women, and $74 \%$ were whites (Response rate $=19.4 \%$ ). The majority $(67 \%)$ of respondents reported that they intended to implement OHPPs in their center within a year. Insufficient funding, lack of enough training in oral health, and limited time to promote oral health were the most frequently cited barriers to implementing OHPPs. CCCDs of non-White race $(p=0.02)$, with a college degree or above $(p=0.05)$, and with positive attitudes $(p<0.0001)$, were more likely to report that they will implement OHPPs within the next year compared to their counterparts.

Conclusions: CCCDs reported fewer barriers to implementing OHPPs within the next year, indicating that CCCs can be a suitable setting to promote oral health. CCCDs race, educational status and attitudes towards oral health strongly predicted their intention to implement OHPPs. Though this study assessed the intention of CCCDs to implement OHPPs in CCCs, it did not access the actual implementation of OHPPs by them. Therefore future research could longitudinally assess predictors for true implementation of OHPPs. In addition, researchers should adopt a more comprehensive, multi-level approach to assess the actual dental health needs of children attending these centers, along with parental, staff and center level characteristics, and other relevant factors related to implementing OHPPs.
\end{abstract}

Keywords: Child care centers, Day care centers, Oral Health, Oral Health Promotion, Pediatric Oral Health Knowledge, Pediatric Health

\footnotetext{
* Correspondence: Vinodh.Bhoopathi@temple.edu

${ }^{4}$ Department of Pediatric Dentistry and Community Oral Health Sciences,

Temple University Maurice H. Kornberg School of Dentistry, 3223 N Broad

Street, Philadelphia, PA 19140, USA

Full list of author information is available at the end of the article
} 


\section{Background}

Dental caries remains a significant health issue among children, with a substantial number of children aged 2 to 15 experiencing dental caries in one or more primary and/ or permanent teeth. Data from the 2011-2012 National Health and Nutrition Examination Survey (NHANES), shows that at least 1 in every 5 children aged 2 to 5 years, and approximately 3 in 5 children aged 6 to 8 had dental caries in their primary teeth [1]. Caries prevalence is higher for children aged 12 to 15, with approximately $50 \%$ experiencing dental caries in one or more teeth by that age [1].

The rise of dual working parents, along with single parent households, has led to an increase in the use of out of home child care arrangements in the United States [2, 3]. In 2011, 32.7 million children were in a regular out of home childcare arrangement, out of which, approximately 12.5 million children were 0 to 4 years of age, and 20.2 million children were 5 to 14 years of age [4]. Twenty five percent of these children were in some form of organized facility such as day care or child care centers (CCCs) [4]. In a previous study assessing the dental needs of children in CCCs, approximately $9 \%$ of the children had an urgent need for dental treatment, while almost 2 in 5 children aged 71 months or younger were diagnosed with early childhood caries (ECC) [5]. With substantial numbers of children spending time in organized facilities such as CCCs, specifically at this especially susceptible age range for dental caries, it is expected that the CCCs take adequate measures to counteract this epidemic.

In 2011, the American Academy of Pediatric Dentistry (AAPD) adopted its "Policy on Oral Health in Child Care Centers," which provides guidance for implementing oral health promotion practices (OHPPs) in out-of-home child care settings [6]. This policy encourages CCCs to implement appropriate OHPPs out of the 14 recommended to reduce a child's risk of acquiring ECC within their centers. Some of the OHPPs include promoting dental home concept to staff and parents, maintaining dental records for children and an up-to-date emergency and trauma manual, providing optimally fluoridated water to the children, in-service training programs for personnel regarding oral hygiene concepts, proper nutrition choices, minimizing saliva sharing practices, and providing well-balanced and nutrient dense diets.

However, most states' CCCs regulations insufficiently promote good oral health [7]. One study examined CCCs implementation of major dental health related standards and identified very low oral health content within state regulations specific to dental health prevention [8]. One study that assessed 8 oral health standards (tooth brushing frequency, tooth brush labeling, toothbrush storage, toothbrush availability, tooth brush maintenance, tooth paste availability, oral health screening, and dental contact information) for out of home child care programs across different states identified that the mean number of standards covered per state was only 2.6 out of 8 possible standards [8]. A recent study in Wisconsin declared a need to increase OHPPs in statefunded centers, indicating that OHPPs in CCCs may be inadequate [9].

In general, children in Florida have difficulty accessing dental care, and they may have impending oral health needs [10]. Only $28.6 \%$ of Medicaid-enrolled Floridian children aged 1 to 20 received any dental services in 2012, with only 18.8 and $10.3 \%$ receiving any preventive dental or dental treatment services respectively [11]. With substantial proportions of children spending time away from their parents in some form of organized facility [4], it is logical to assume that there would be benefits to using these nontraditional settings to promote children's oral health. However, to ascertain whether CCCs are an appropriate setting for oral health promotion and disease prevention, understanding barriers in implementing OHPPs within these centers is pertinent. One factor that may determine OHPPs being implemented within these centers is the willingness of the child care center directors (CCCDs) to do so. CCCDs have a significant role in implementing any health promotion programs within their CCCs. Therefore, this study aims to determine CCCDs intention to implement OHPPs within the next year in licensed Florida CCCs, factors associated with their intention to implement, and various barriers that may impede CCCDs from implementing OHPPs in CCCs.

\section{Methods}

\section{Design and sample}

The Institution Review Board at the Nova Southeastern University Health Professions Division approved this cross-sectional study. The Florida Department of Children and Families maintains an updated, statewide email list of licensed CCCDs, which is publically available and was used for sampling purposes. In January 2014, an email list, although not exhaustive, was available for 5142 licensed Florida CCCDs, and requests for survey participation were made using Survey Monkey (www.surveymonkey.com). Before administering the 45-item online survey it was pilot tested with 10 CCCDs. Reminders were sent every two weeks after the initial online request, with a total of 3 reminders. The survey was open for completion over a 3-month period (January to March 2014).

\section{Measures \\ Main independent variables}

Pediatric Oral Health Knowledge (POHK) POHK of CCCDs was measured using 3 questions asking about 
the age when someone should start cleaning a child's mouth (Correct answer: As soon as tooth erupts), age of first dental visit (correct answer: 1 year), and the most common childhood disease in children (correct answer: tooth decay or cavities). These questions were adapted from a prior study assessing the pediatric oral health knowledge of mothers and guardians [12]. All correct responses were given a score of 1 , while incorrect responses were coded as 0 . The responses were summed to derive a composite POHK score (Score range: 0 to 3 ) with higher scores indicating that the POHK of the CCCD was high.

Attitudes about Pediatric Oral Health (APOH) $\mathrm{APOH}$ in CCCDs was measured by asking 4 questions that were adapted from a previous study by Mathu-Muju et al. [13]. A 5-point Likert scale (Strongly Agree to Strongly Disagree) was used to rate following statements: 1) cleaning baby teeth is not important, 2) too many other activities to focus on so there is no time for oral health promotion activities, 3) difficult to teach children younger than 3 years old about dental health, and 4) providing oral health promotion activities at the center will prevent tooth decay. The responses from the 4 questions were summed to derive a composite $\mathrm{APOH}$ score (Score range: 0 to 20). A higher APOH score indicates positive APOH. The 5-item Likert scales for 4 $\mathrm{APOH}$ questions demonstrated an acceptable internal consistency reliability estimate (Cronbach's alpha $=$ $0.70)$ with this sample.

Self-perceived barriers to implementing OHPPs To determine the self-perceived barriers that may impede implementing OHPPs within their centers, we asked them to choose from a list of items using a check box option. The respondents were prompted to check all the items that may apply. The researchers developed these items. The list of items (or barriers) included: 1) lack of funding, 2) negative attitudes of parents, 3) cultural or religious beliefs of parents/caregivers, 4) language barriers of parents/caregivers, 5) insufficient oral health training of staff, 6) insufficient space, 7) lack of time, and 8) infection control concerns. We also included an open-ended option allowing CCCDs to indicate additional barriers. All checked responses were coded 1, while non-checked responses were coded 0 . A new variable was created and coded 1 for negative responses to the open-ended option, and 0 for no responses. The responses for all items were summed to derive a composite barrier score ranging from 0 to 9 , with higher scores indicating higher number of CCCDs self-perceived barriers (and therefore greater difficulty) to implementing OHPPs in CCCs.

\section{Main outcome variable}

Intention to implement OHPPs The CCCDs were asked if they intend to implement any OHPPs for the children in their center within a year, with a Yes/No response category.

\section{Analysis}

Analyses were performed using SAS statistical analysis software (SAS Institute, Inc. Cary, N.C.) version 9.3. Univariate statistics were utilized for the following main independent variables: CCCD's age, gender (Male vs females), ethnicity (Hispanics vs Non-Hispanics), race (Whites vs non-Whites), education (College degree and above vs Less than a college degree), annual income ( $>=\$ 50,000$ per year vs $<\$ 50,000)$, CCCDs years of experience working at a CCC, POHL, APOH, and selfperceived barriers. One multivariate adjusted logistic regression model determining CCCDs intention to implement OHPPs within the next year in their CCC was created, adjusting for the above-mentioned independent variables. We performed multicollinearity diagnostic analysis and determined that no collinearity existed between the main independent variables.

\section{Results}

Fifty-three CCCDs opted out of study participation, and 631 email addresses were invalid. Responses from 877 participants were received, yielding an overall response rate of $19.4 \%(877 / 4511)$. The mean age of the study participants was $48.5 \pm 10.5$ years.

Table 1 provides an overview of the study sample's demographic characteristics. The majority of the respondents were women (96\%). Nineteen percent of the respondents self-identified as belonging to the Hispanic ethnicity. The sample was predominantly White (74\%); while Black/African Americans made up $22 \%$ of the sample. The remainder of the sample identified their race as "other" (3\%), Asian (1\%), and Native Hawaiian/ Pacific Islander (0.2 \%). Sixty-five percent of the respondents reported having earned a college degree or higher. Approximately $61 \%$ reported earning an annual income of less than $\$ 50,000$.

Fewer than $20 \%$ of respondents correctly answered "no" when asked if the age to start cleaning a child's mouth was 1 year, and only $35 \%$ correctly knew that a child's first dental visit should not be at 2 years (Table 2). However, $84 \%$ of respondents correctly identified tooth decay as the most common childhood disease. The overall mean POHK score was low at $1.3 \pm 0.8$ (mean $\pm \mathrm{SD}$ ) out of a maximum score of 3.

The attitudes of CCCDs are described in Table 2. We found that the majority (94\%) of respondents agreed that cleaning baby teeth was important to the overall 
Table 1 Demographic characteristics of participating Florida childcare center directors

\begin{tabular}{|c|c|}
\hline Gender & $\%$ \\
\hline Female & $96 \%$ \\
\hline Male & $4 \%$ \\
\hline \multicolumn{2}{|l|}{ Ethnicity } \\
\hline Not Hispanic or Latino & $81 \%$ \\
\hline Hispanic or Latino & $19 \%$ \\
\hline \multicolumn{2}{|l|}{ Race } \\
\hline American Indian or Alaska Native & $0 \%$ \\
\hline Asian & $1 \%$ \\
\hline Black or African American & $22 \%$ \\
\hline Native Hawaiian or Other Pacific Islander & $0.2 \%$ \\
\hline White & $74 \%$ \\
\hline Other & $3 \%$ \\
\hline \multicolumn{2}{|l|}{ Highest level of formal education completed } \\
\hline High school diploma/GED & $5 \%$ \\
\hline Some College & $22 \%$ \\
\hline Vocational/Technical College & $8 \%$ \\
\hline College Degree & $46 \%$ \\
\hline Post-graduate degree & $19 \%$ \\
\hline \multicolumn{2}{|l|}{ Income } \\
\hline $0-\$ 15,999$ & $3 \%$ \\
\hline$\$ 16,000-\$ 29,999$ & $20 \%$ \\
\hline$\$ 30,000-\$ 49,999$ & $38 \%$ \\
\hline$\$ 50,000-\$ 69,999$ & $14 \%$ \\
\hline$\$ 70,000$ and above & $7 \%$ \\
\hline Prefer not to answer & $18 \%$ \\
\hline
\end{tabular}

health of the child. Most disagreed that there were too many activities in CCCs to focus on oral health (77\%), and that teaching children younger than 3 years old about oral health was too difficult (87 \%). However, only $68 \%$ of the participants agreed that providing oral health promotion activities in the center would prevent dental caries. The overall mean $\mathrm{APOH}$ score for the sample was $16.8 \pm 2.7$ (mean $\pm \mathrm{SD}$ ) out of a maximum score of 20 , indicating positive attitudes towards oral health.

A majority (67\%) of the respondents reported that they were intending to implement OHPPs for children in their center within the next year. Figure 1 illustrates the frequency of reported barriers they will face in implementing OHPPs within their centers. The most frequently selected self-perceived barrier was financial constraints (38.5\%), followed by insufficient training of the staff to promote oral health $(32.7 \%)$ and lack of time $(24.7 \%)$. Family/parent's language $(6.6 \%)$ or cultural backgrounds $(5.4 \%)$ were the least likely to be perceived as barriers by the
Table 2 Childcare center directors' oral health knowledge and attitudes

Oral Health Knowledge

Start cleaning child's mouth at the age of 1 . $\%$

Yes $\quad 82 \%$

$\mathrm{No}^{\mathrm{a}} \quad 18 \%$

The first dental visit for a child should be at 2 years.

True $\quad 65 \%$

False $^{{ }^{a}} \quad 35 \%$

Most common childhood disease in children under 7 years of age

Asthma $\quad 13 \%$

Hay fever $1 \%$

Tooth decay or cavities ${ }^{\text {a }} \quad 84 \%$

Chicken Pox $\quad 2 \%$

Attitudes

Cleaning baby teeth is not that important \%

Strongly agree $\quad 2 \%$

Agree $\quad 1 \%$

Not sure $\quad 3 \%$

Disagree $\quad 19 \%$

Strongly disagree $\quad 75 \%$

Too many activities to devote any time to dental health

$\begin{array}{ll}\text { Strongly agree } & 2 \% \\ \text { Agree } & 7 \% \\ \text { Not sure } & 14 \% \\ \text { Disagree } & 42 \% \\ \text { Strongly disagree } & 35 \%\end{array}$

Teaching children younger than 3 years of age about dental health is too difficult

$\begin{array}{ll}\text { Strongly agree } & 2 \% \\ \text { Agree } & 3 \% \\ \text { Not sure } & 7 \% \\ \text { Disagree } & 42 \% \\ \text { Strongly disagree } & 45 \%\end{array}$

Don't believe the activities provided in the center will prevent cavities Strongly agree $\quad 3 \%$

Agree $\quad 9 \%$

Not sure $\quad 20 \%$

Disagree $\quad 34 \%$

Strongly disagree $\quad 34 \%$

Indicate correct answers

CCCDs. The overall mean self-perceived barrier score for the sample was $1.55 \pm 1.64$ (mean $\pm \mathrm{SD}$ ) out of a maximum score of 9 , indicating there were lower selfperceived barriers to implementing OHPPs.

The adjusted logistic regression model determining CCCDs intention to implement OHPPs within the next 


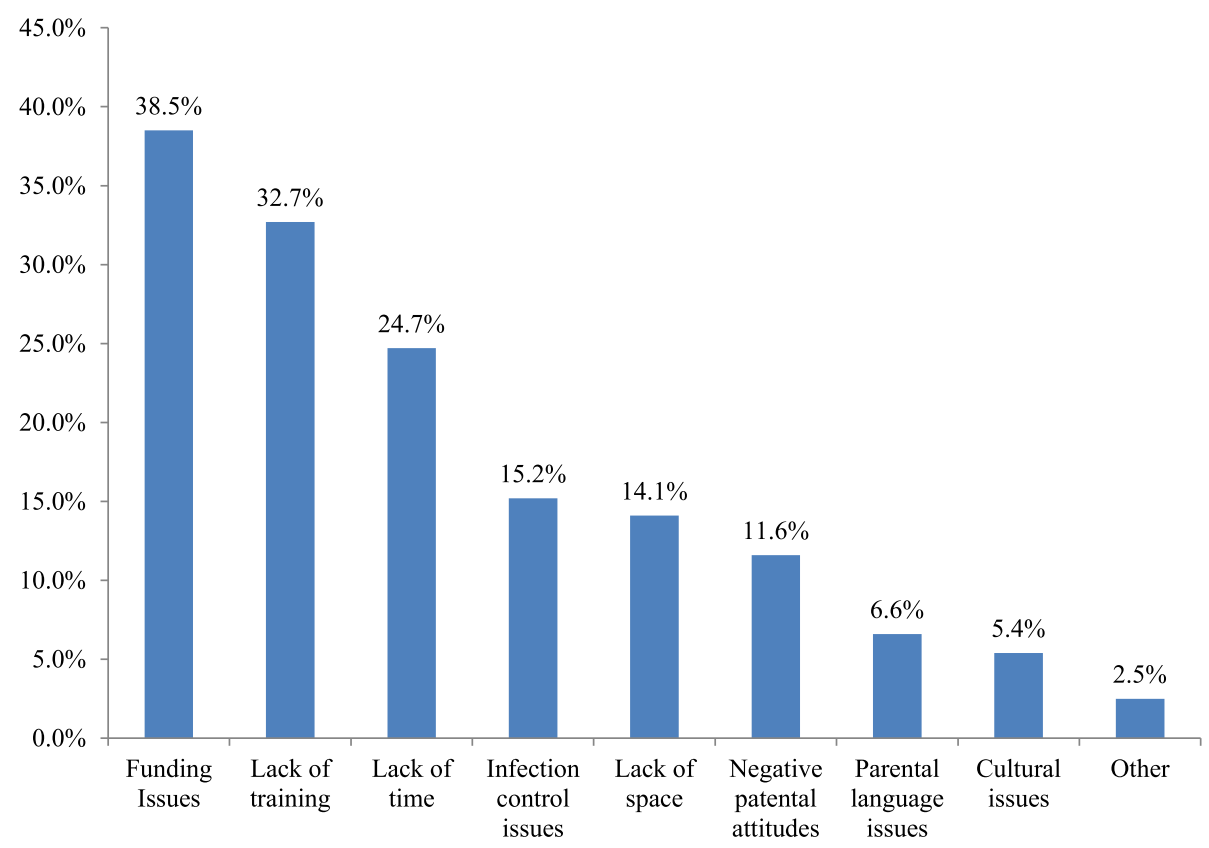

Fig. 1 Self-perceived barriers in implementing OHPPs as reported by CCCDs

year in their CCCs included the following variables: CCCD's age, gender, race, ethnicity, income, education, years of experience as a CCCD, POHK, APOH, and selfperceived barriers (Table 3). Results showed that CCCDs of non-White origin $(p=0.02)$, who had a college degree or above $(p=0.05)$, and those with positive attitudes towards pediatric oral health $(p<0.0001)$ were significantly more likely to report that they intend to implement OHPPs within their CCC in the upcoming year.

\section{Discussion}

A PEW Centers' report indicated that Florida's children have difficulty accessing dental care, and that they may have impending oral health needs [10]. Currently, many children spend a large amount of time away from their parents in some form of child care arrangement. Due to the extended period of time in CCCs, the possibility of using these non-traditional settings to promote children's oral health would be beneficial. Successfully implemented prevention standards or programs depend on the CCCDs efforts and willingness to promote health of the children attending CCCs. Therefore, our study targeted CCCDs in licensed Florida CCCs to examine whether they intended to implement any OHPPs within the next year, factors associated with implementing OHPPS, and the barriers they foresee that may impede the successful implementation of OHPPs .

Results show that while few self-perceived barriers to promote oral health in CCC were identified, the three most common barriers cited by the directors were

Table 3 Regression model determining CCCDs intention to implement OHPPs within a year in their center

\begin{tabular}{|c|c|c|c|}
\hline Variables of interest & Odds ratio & $95 \% \mathrm{Cl}$ & $p$-value \\
\hline Age (higher number) & 0.99 & $0.97-1.01$ & 0.55 \\
\hline Gender (Males vs females) & 1.04 & $0.35-3.14$ & 0.94 \\
\hline Race (Whites vs Non-whites) & 0.59 & $0.37-0.94$ & 0.02 \\
\hline Ethnicity (Hispanics vs Non-Hispanics) & 1.31 & $0.76-2.08$ & 0.36 \\
\hline Income (> = 50,000 vs. $<50,000)$ & 0.76 & $0.49-1.19$ & 0.23 \\
\hline Education (College degreee and above vs < college degree) & 1.5 & $1.04-2.27$ & 0.05 \\
\hline Years of experience as CCCD (higher number) & 1.01 & $0.99-1.04$ & 0.3 \\
\hline Pediatric Oral health knowledge (higher number) & 1.04 & $0.81-1.33$ & 0.76 \\
\hline Attitudes towards pediatric oral health (higher number) & 1.2 & $1.08-1.27$ & $<0.0001$ \\
\hline Self-perceived barriers (higher number) & 0.9 & $0.8-1.01$ & 0.07 \\
\hline
\end{tabular}


institutionally driven. Insufficient funding, lack of enough training, and limited time to promote oral health were the most frequently cited reasons. Evidence shows that these three elements are extremely crucial for promoting any effective health promotion or disease prevention program in a CCC [14]. For example, with adequate funding, time, and training, nutritional professionals successfully taught child care staff and directors adopt and operationalize obesity prevention guidelines, thereby creating a supportive feeding environment [14]. Our findings indicate that until the social/structural barriers (money, training, time) at the institutional level are addressed and resolved, successful implementation of effective oral health promotion/interventions may not be possible.

Multivariate modeling showed that CCCD's who were willing to implement OHPPs in the next year were more likely to be of non-White race, with a college degree or above, and those with better attitudes about pediatric oral health. It is unclear, why CCCDs who identified as racial minorities were more willing to implement OHPPs within the next year, compared to Whites. The literature shows contradictory findings regarding racial/ethnic minorities adopting preventive behaviors compared to Whites [15-17]. Evidence shows that child care staffs with a formal college education or above provide more sensitive and appropriate care to children with asthma [18]. Similarly, our study found that CCCDs with at least a formal college education were more willing to implement OHPPs compared to their counterparts, indicating that someone with higher educational status may understand the importance of implementing OHPPs. Directors with a college degree and above responded more favorably to implementing OHPPs. Therefore, institutions recruiting CCCDs should hire someone with a college a degree and above. Additional training on the importance of oral health for those with low level of education might improve their intention to implement OHPPs. Participants with more positive attitudes about pediatric oral health reported more OHPS implemented in their centers. Evidence shows that those with positive attitudes about maintaining health tend to adopt healthy behaviors themselves [19].

To our knowledge, this is the first study to assess CCCDs' willingness to implement OHPPs in licensed CCCs, especially in the State of Florida. This study is not without limitations, such as low survey response rate. Low response rates in survey research can influence the findings, and the generalizability (external validity) of the results. Moreover, caution in data interpretation is warranted when data is self-reported, and not observed. The use of a convenience sample of CCCDs working in licensed CCCs did not allow us to survey non-licensed centers, which would have provided more comprehensive and diverse data. Other CCCs, such as family based childcare homes or faith-based centers that provide childcare on a daily basis were not included in this study. In addition, we did not identify if CCCs were a part of a large company or a franchise where barriers for implementing OHPPs may be different compared to a CCC associated with a small business. Selective participation could have introduced bias, with respondents being more interested in the topic compared to nonrespondents, raising the possibility that our results overestimate the attitudes for all Florida licensed CCCDs. CCCDs intention to implement may not always translate into actual implementation of OHPPs, and because we did not follow this cohort longitudinally, it was not possible to determine if the CCCDs actually implemented any OHPPs within the next year.

Future research could longitudinally assess predictors for actually implementing OHPPs. In this kind of environment, research should highlight whether good intentions and/or low self-perceived barriers actually translate into successful implementation of OHPPs, or whether perceived barriers are the strongest predictor of successful implementation. In addition, researchers should adopt a more comprehensive, multi-level approach to assess the actual dental health needs of children attending these centers, along with parental, staff and center level characteristics, and other relevant factors related to implementing more OHPPs. Such a study should also include all types of CCCs (e.g., family based, faith based, school based) and how these multilevel factors interplay to impact the oral health of children.

\section{Conclusions}

CCCs are an appropriate and innovative setting for dental disease prevention and oral health promotion. Novel programs can be adopted in these centers to prevent dental diseases and promote good oral health behaviors among child enrollees. Implementing simple oral health promotion strategies in CCCs, may have a major impact on the oral health of the children. CCCDs in this study reported low overall oral health knowledge, and therefore, it is dental professionals' and dental associations' responsibility to educate the CCCDs, including the staff at the CCC, and the parents of the children to promote good oral hygiene in children.

\section{Abbreviations}

AAPD: American Academy of Pediatric Dentistry; APOH: Attitudes about Pediatric Oral Health; CCCDs: Child care center directors; CCCs: Child care centers; OHPPs: Oral health promotion practices; POHK: Pediatric Oral Health Knowledge

\section{Acknowledgements}

The authors would like to thank to the child care center directors who voluntarily participated in the study. 


\section{Funding}

This study was supported by the Nova Southeastern University Health Professions Division research funding. Grant \#335548.

\section{Availability of data and materials}

Data cannot be shared at this time because more publications are being written using the same data.

\section{Authors' contributions}

AJ data collection, manuscript writing, critical editing. RO Study design, manuscript writing, critical editing of the manuscript. RJ Study design, data analysis, and critical editing of the manuscript for important intellectual content. VB Conceptualization, study design, data collection and analysis, writing manuscript, critical editing of the manuscript for important intellectual content. All authors read and approved the final manuscript.

\section{Authors' information}

Dr. Ajay Joshi was a pediatric dental resident at Nova Southeastern University College of Dental Medicine when this thesis study was conducted. Currently he is an Assistant Clinical Professor at Indiana University School of Dentistry and maintains his private practice in Marion, IN. Dr. Romer Ocanto is Associate Professor, and Chair of Pediatric Dentistry at Nova Southeastern University. Dr. Robin J. Jacobs is Associate Professor of Psychiatry and Behavioral Medicine, Associate Professor of Biomedical Informatics, and Associate Professor of Public Health at Nova Southeastern University. Dr. Vinodh Bhoopathi, was an Assistant Professor at Nova Southeastern University College of Dental Medicine, and the thesis committee chair when this study was conducted. Currently he is an Assistant Professor at the Temple University Maurice H Kornberg School of Dentistry, Philadelphia, PA. Address correspondence to Dr. Bhoopathi. E-mail: Vinodh.Bhoopathi@temple.edu.

\section{Competing interests}

The authors declare that they have no competing interests.

\section{Consent for publication}

Not applicable.

\section{Ethics approval and consent to participate}

This study was approved by the Institution review board (IRB) at the Nova Southeastern University Health Professions Division (Protocol: CGG2013-19). Participation was voluntary and anonymous, and participants were informed about the purpose and protocol of the study.

\section{Author details}

${ }^{1}$ Pediatric Dentistry Department, Indiana University School of Dentistry, 1121 W. Michigan Street, Indianapolis, IN 46202, USA. ²Department of Pediatric Dentistry, Nova Southeastern University College of Dental Medicine, 3200 S University Drive, Fort Lauderdale, FL 33328, USA. ${ }^{3}$ Psychiatry and Behavioral Medicine, College of Osteopathic Medicine, Nova Southeastern University, 3200 S. University Drive, Fort Lauderdale, FL 33328, USA. ${ }^{4}$ Department of Pediatric Dentistry and Community Oral Health Sciences, Temple University Maurice H. Kornberg School of Dentistry, 3223 N Broad Street, Philadelphia, PA 19140, USA.

Received: 2 July 2016 Accepted: 16 September 2016 Published online: 22 September 2016

\section{References}

1. Dye BA, Thornton-Evans G, Li X, lafolla TJ. Dental caries and sealant prevalence in children and adolescents in the United States, 2011-2012. NCHS data brief, no 191. Hyattsville: National Center for Health Statistics; 2015.

2. Laughlin L. Who's minding the kids? Child care arrangements: Spring 2011 Current population reports. Washington, DC: U.S. Census Bureau; 2013. p. 70-135. Available at: https://www.census.gov/prod/2013pubs/p70-135.pdf Accessed 09 March 2015.

3. Fox L, Han WJ, Ruhm C, Waldfogel J. Time for children: trends in the employment patterns of parents, 1967-2009. Demography. 2013;50:25-49.
4. United States Census Bureau. Child Care an Important Part of American Life. How do we know? Available at: http://www.census.gov/how/pdf/child_care. pdf. Accessed 15 June 2015.

5. Southward LH, Robertson A, Edelstein BL, Hanna H, Wells-Parker E, Baggett DH, Eklund NP, Crall JJ, Silberman SL, Parrish DR. Oral health of young children in Mississippi Delta child care centers: a second look at early childhood caries risk assessment. J Public Health Dent. 2008;68(4):188-95.

6. Policy on oral health in child care centers. Council on Clinical Affairs, American Academy of Pediatric Dentistry; 2011. Available at http://www aapd.org/media/policies_guidelines/p_ohccarecenters.pdf. Accessed 16 Sept 2016.

7. Kranz AM, Rozier RG. Oral health content of early education and child care regulations and standards. J Public Health Dent. 2011;11:81-90.

8. Kim J, Kaste LM, Fadavi S, et al. Are state child care regulations meeting national oral health and nutritional standards? Pediatr Dent. 2012:34:317-24.

9. Scheunemann D, Schwab M, Margaritis V. Oral health practices of state and non-state-funded licensed childcare centers in Wisconsin, USA.J Int Soc Prev Community Dent. 2015;5:296-301.

10. The Pew Center of States. May 2011. The State of Children's Dental Health: Making Coverage Matter. The Pew Charitable Trusts. Available at http://www.pewtrusts.org/ /media/legacy/uploadedfiles/ wwwpewtrustsorg/reports/state_policy/ childrensdental50statereport2011pdf.pdf. Accessed 12 June 2016

11. Childrens use of dental care in Medicaid: Federal fiscal year 2000-2012. The George Washington Universty, 2014. Available at https:/www.medicaid.gov/ medicaid-chip-program-information/by-topics/benefits/downloads/dentaltrends-2000-to-2012.pdf. Accessed 15th May 2016.

12. Akpabio A, Klausner CP, Inglehart MR. Mothers'/guardians' knowledge about promoting children's oral health. J Dent Hyg. 2008;82:12.

13. Mathu-Muju KR, Lee JY, Zeldin LP, Rozier RG. Opinions of Early Head Start staff about the provision of preventive dental services by primary medical care providers. J Public Health Dent. 2008;68:154-62.

14. Sigman-Grant M, Christiansen E, Fernandez G, Fletcher J, Johnson SL, Branen L, Price BA. Child care provider training and a supportive feeding environment in child care settings in 4 states, 2003. Prev Chronic Dis. 2011;8:A113.

15. SteelFisher GK, Blendon RJ, Kang M, Ward JR, Kahn EB, Maddox KE, Lubell KM, Tucker M, Ben-Porath EN. Adoption of preventive behaviors in response to the 2009 H1N1 influenza pandemic: a multiethnic perspective. Influenza Other Respir Viruses. 2015;9:131-42.

16. Kong A, Beresford SA, Imayama I, Duggan C, Alfano CM, Foster-Schubert KE, Neuhouser ML, Johnson DB, Wang CY, Xiao L, Bain CE, McTiernan A Adoption of diet-related self-monitoring behaviors varies by race/ethnicity, education, and baseline binge eating score among overweight-to-obese postmenopausal women in a 12-month dietary weight loss intervention. Nutr Res. 2012;32:260-5.

17. Nayak P, Paxton RJ, Holmes H, Thanh Nguyen H, Elting LS. Racial and ethnic differences in health behaviors among cancer survivors. Am J Prev Med. 2015:48:729-36.

18. Whitebook M, Howes C, Phillips D. The National Child Care Staffing Study. Washington DC: The Center for the Child Care Workforce; 1998. p. 43.

19. Lino S, Marshak HH, Herring RP, Belliard JC, Hilliard C, Campbell D, Montgomery S. Using the theory of planned behavior to explore attitudes and beliefs about dietary supplements among HIV-positive Black women. Complement Ther Med. 2014;22:400-8. 